\title{
COMPARATIVE EFFICACY OF GLYCOSAMINOGLYCANS EXTRACTED FROM CHICKEN KEEL CARTILAGE AND FISH ON CLINICAL SIGNS OF OSTEOARTHRITIS AND C-TERMINAL TELOPEPTIDES OF TYPE II COLLAGEN
}

\author{
Humaira Majeed Khan', Aftab Ahmad Anjum², Muhammad Ashraf ${ }^{3}$ and Mansur-ud-Din \\ Ahmad $^{4}$ \\ ${ }^{1}$ Institute of Pharmacy, Lahore College for Women University, Jail Road, Lahore-54000, Pakistan; ${ }^{2}$ Department of \\ Microbiology, ${ }^{3}$ Department of Pharmacology and Toxicology; ${ }^{4}$ Department of Epidemiology and Public Health, \\ University of Veterinary and Animal Sciences, Lahore-54000, Pakistan. \\ "Corresponding author's e-mail: aftab.anjum@uvas.edu.pk
}

Chondroitin sulphate (CS) and glucosamine sulphate (GS), building blocks of Glycosaminoglycans are effectively used in the treatment of Osteoarthritis in human beings. Aim of the present study was to evaluate the efficacy of Glycosaminoglycans, extracted from chicken keel cartilage and fish, on clinical signs of Osteoarthritis and C-terminal telopeptides of type II collagen (CTX-II). The clinical signs scored from $28^{\text {th }}$ day of induced Osteoarthritis till $60^{\text {th }}$ day of treatment were pain threshold, degree of lameness and swelling. Serum concentrations of CTX-II were determined s by Enzyme linked immunosorbent assay (ELISA). Highest mean pain score was recorded in OA un-treated followed by treated rats with GS, standard CS, extracted CS, extracted CS plus GS and standard CS plus GS. Respective pattern was observed among treated and un-treated groups in relation to lameness. There was non-significant difference among swelling scores of induced un-treated and treated groups with extracted and standard CS. No clinical sign was observed in control group. Highest serum concentration of CTX II (pg/ml) was recorded in un-treated OA group (36.70 \pm 3.57$)$, followed by groups treated with GS alone (6.12 \pm 0.13$)$, standard CS (4.48 \pm 0.44$)$, sample CS (4.40 \pm 0.50$)$, GS plus sample CS (2.74 \pm 0.62$)$, GS plus standard CS (2.62 \pm 0.66$)$ and normal group $(2.55 \pm 0.10)$. Results of CS extracted from poultry were comparable in efficacy with standard CS from fish source (shark) alone and in combination with GS.

Keywords: Glycosaminoglycans, pain, lameness, swelling, CTX-II, Osteoarthritis.

\section{INTRODUCTION}

Osteoarthritis (OA) is characterized by low grade inflammation leading to progressive degenerative changes in articular cartilage (Morenko et al., 2004). Joint mobility is reduced owing to pain and swelling of affected area. Severity of OA depends on type of inducer that may be chemical, enzymatic or surgical. Cartilage metabolic disturbances lead to destabilization and degeneration. Clinical manifestations of OA include softening, fibrillation, ulceration, sclerosis, bone eburnation, osteophytes and sub-chondral cysts formation (Fernihough et al., 2004). Pain leading to joint immobilization is prominent manifestation of this chronic malady (Khan et al., 2012). Initially, soft swelling can be observed on affected joints which later on subside with the progression of diseases. Crackling sounds from affected joints during walking and standing (Brandt et al., 2009). Mostly, treatment of OA is done focusing the symptom of pain and joint dysfunction (Flood, 2010). Non-steroidal anti-inflammatory drugs (NSAIDS), opiates, corticosteroids and nutraceuticals are conventional therapeutics for OA (Sofat et al., 2011).
Glycosaminoglycans (GAGs) are long un-branched polysaccharides of repeating disaccharide units abundantly present in connective tissues, vitreous humor, synovial fluid, mast cells and predominately in cartilages. The major constituents are chondroitin sulphate, dermatan sulphate, heparin/heparansulphate, glucosamine and hyaluronic acid. Among these, glucosamine sulphate (GS) and chondroitin sulphate (CS) are more effective and safe therapeutic agents for OA (Miller and Clegg, 2010). CS and GS stimulate chondrocyte synthesis of collagen (Adams et al., 2013). Concurrent use of CS and GS increase synthesis of cartilage matrix and decrease progression of OA which ultimately reduces signs and symptoms of disease. In present study, efficacy of glycosaminoglycans on clinical signs of osteoarthritis and C-terminal telopeptides of type II collagen (CTX-II) was evaluated in papain induced OA albino rat model.

\section{MATERIALS AND METHODS}

A total of 35 albino rats (4 weeks old) were purchased and 
Khan, Anjum, Ashraf \& Ahmad

Table 1. Efficacy of chondroitin sulfate alone and in combination with glucosamine sulfate using papain induced osteoarthritis rat model (Mean \pm SD).

\begin{tabular}{llllc}
\hline Treatments & Swelling $(\mathbf{m m})$ & Pain (sec.) & Lameness & Total clinical score \\
\hline Untreated Group (Normal) & $0.00 \pm 0.00 \mathrm{a}$ & $0.00 \pm 0.00 \mathrm{a}$ & $0.00 \pm 0.00 \mathrm{a}$ & $0.00 \pm 0.00 \mathrm{a}$ \\
OA group & $0.54 \pm 0.28 \mathrm{abc}$ & $2.61 \pm 0.18 \mathrm{~d}$ & $1.00 \pm 0.00 \mathrm{~b}$ & $4.15 \pm 0.38 \mathrm{c}$ \\
Treated group (Glucosamine) & $1.04 \pm 0.50 \mathrm{c}$ & $1.56 \pm 0.70 \mathrm{c}$ & $0.60 \pm 0.55 \mathrm{ab}$ & $3.19 \pm 1.28 \mathrm{bc}$ \\
Treated group (Chondroitin standard) & $0.71 \pm 0.68 \mathrm{abc}$ & $1.53 \pm 0.40 \mathrm{c}$ & $0.40 \pm 0.55 \mathrm{ab}$ & $2.64 \pm 1.18 \mathrm{~b}$ \\
Treated group (Chondroitin sample) & $0.72 \pm 0.66 \mathrm{abc}$ & $1.14 \pm 0.27 \mathrm{bc}$ & $0.40 \pm 0.55 \mathrm{ab}$ & $2.26 \pm 1.33 \mathrm{~b}$ \\
Treated group (Chondroitin standard plus glucosamine) & $0.12 \pm 0.13 \mathrm{ab}$ & $0.62 \pm 0.60 \mathrm{~b}$ & $0.20 \pm 0.45 \mathrm{a}$ & $0.94 \pm 0.78 \mathrm{a}$ \\
Treated Group (Chondroitin sample plus glucosamine) & $0.15 \pm 0.30 \mathrm{ab}$ & $0.70 \pm 0.70 \mathrm{~b}$ & $0.20 \pm 0.45 \mathrm{a}$ & $1.05 \pm 0.59 \mathrm{a}$ \\
\hline
\end{tabular}

Mean \pm S.D with same superscripts differ non-significantly whereas numeric values with different superscripts vary significantly.

maintained at Animal house of University of Veterinary and Animal Sciences, Lahore on standard diet with continuous air refreshment. Rats were divided into 7 groups ( $\mathrm{n}=5$, each) including healthy control group, OA group and five treatment groups. Osteoarthritis (OA) was induced in all groups, except healthy control, on $28^{\text {th }}$ day by using papaine as described by Khan et al., (2012). Treatment groups were given glucosamine sulfate (GS), chondroitin sulfate (CS) extracted from poultry, standard CS (Shark), extracted CS plus GS and standard CS plus GS from day 28 to 60 . OA group was remained un-treated. CS and GS were administered @ $1.2 \mathrm{~g} / \mathrm{Kg}$ and $1.5 \mathrm{~g} / \mathrm{Kg}$ body weight, respectively, daily by oral route. Treatments were given by mixing the respective compounds in rat feed $(10 \mathrm{~g})$. Healthy and OA un-treated groups were offered feed without any drug. On $60^{\text {th }}$ day, clinical parameters including pain severity, degree of lameness and swelling of affected knee joint were recorded. On $60^{\text {th }}$ day, rats were euthanized and $5 \mathrm{ml}$ blood was drawn directly from heart of all rats.

Clinical scores: Efficacy of GS and CS (alone and in combinations) in terms of clinical scores for pain, lameness and swelling was evaluated. Pain threshold was assessed by hot water tail $\left(55^{\circ} \mathrm{C}\right)$ flick assay (Jones et al., 2012) and latency time (seconds) to flick the tail. Distal third of rat's tail was dipped in hot water bath and time required to flick tail from heat stimuli was counted using stop watch. The tail flicking score was calculated as mean of three readings separated with an interval of 30 seconds. Recorded latency time was graded as $0.1-1,1.1-2.0,2.1-3.0$ and 3.1-4.0 seconds and a score of 01, 02, 03 and 04 was allotted, respectively. Degree of lameness was recorded by ordinal scoring system and graded as mild, less moderate, moderate and severe with allocated scores 01, 02, 03 and 04, respectively. Knee diameter of swollen joints was measured (mm) by calibrated digital caliper (Fernihough et al., 2004). Knee diameter ranges of 0.1-2, 2.1-4.0, 4.1-6.0 and 6.1-8.0 millimeters were scored as 01, 02, 03, and 04, respectively.

Biomarker estimation: CTX-II was estimated using serum preclinical CartiLaps ${ }^{\circledR}$ enzyme linked immunosorbant assay (ELISA) kit (Immunodiagnostic system, UK. cat \# AC-081) as described by Garvican et al. (2010). Concentration of CTX-II in sera samples of treated and control groups were calculated from standard curve of known samples.

Clinical scores and CTX-II concentrations were expressed as mean \pm S.D and compared by one way ANOVA followed by Duncan's multiple range tests using SPSS version 16.0 at $\mathrm{p}<0.05$.

\section{RESULTS}

Mean clinical scores of swelling, pain and lameness of OA group were significantly higher $(\mathrm{p}<0.05)$ as compared to normal group. All treatment groups significantly abrogated the clinical scores of swelling and lameness when compared with OA group. GS treated group showed significantly higher swelling score $(p<0.05)$ as compared to other treatment groups and OA group (Table 1). Efficacy of extracted and standard CS in combination with GS was comparable on statistical analysis on the basis of swelling. Highest mean clinical score for pain was recorded in OA un-treated rats (2.61 \pm .18$)$ followed by treated with GS $(1.56 \pm 0.70)$, standard CS (1.53 \pm 0.40$)$, extracted CS (1.14 \pm 0.27$)$, extracted CS plus GS (0.70 \pm 0.70$)$ and standard CS plus GS $(0.62 \pm 0.60)$. Statistical mean score for pain was found to be non-significant $(\mathrm{p}<0.05)$ among rats treated with GS, standard CS and extracted CS. Efficacy of extracted CS was same as of standard CS alone and in combination with GS.

Statistical mean clinical score for lameness observed in OA group was highest $(1.00 \pm .00)$ followed by treated with GS $(0.60 \pm 0.55)$, standard CS $(0.40 \pm 0.55)$, extracted CS $(0.40 \pm 0.55)$, GS plus standard CS $(0.20 \pm 0.45)$ and GS plus extracted CS $(0.20 \pm 0.45)$, respectively. Un-treated induced groups differed significantly with all other groups $(\mathrm{p} \leq 0.05)$.

Concentration of CTX II: Highest statistical mean concentration $(\mathrm{pg} / \mathrm{ml})$ of CTX II in sera samples calculated by ELISA was observed in un-treated induced group (36.70 \pm 3.57$)$ followed by treated with GS alone $(6.12 \pm 0.13)$, standard CS (4.48 \pm 0.44$)$, extracted CS (4.40 \pm 0.50$)$, GS plus extracted CS (2.74 \pm 0.62$)$, GS plus standard CS (2.62 \pm 0.66$)$ and normal $(2.55 \pm 0.10)$, respectively. Statistical mean 
Table 2. Quantitative analysis of CTX II (C-terminal teleopeptide) by sandwich ELISA in sera of osteoarthritis rats treated with chondroitin sulfate alone and in combination with glucosamine sulfate.

\begin{tabular}{|c|c|c|c|c|c|}
\hline Control/ Samples & $\begin{array}{c}\text { No. of } \\
\text { replicates }\end{array}$ & $\begin{array}{c}\text { A450-650 } \\
\text { Obs.1 / Obs.2 }\end{array}$ & $\begin{array}{l}\text { Mean A450- } \\
650(\mathrm{~nm})\end{array}$ & $\begin{array}{c}\text { Interpolated CartiLaps } \\
\text { conc. }(\mathrm{pg} / \mathrm{ml})\end{array}$ & Mean \pm S.D. \\
\hline Untreated Group & 01 & $0.231 / 0.215$ & 0.223 & 4.00 & $2.55 \pm 0.10^{\mathrm{a}}$ \\
\hline \multirow[t]{4}{*}{ (Normal) } & 02 & $0.182 / 0.169$ & 0.176 & 2.50 & \\
\hline & 03 & $0.145 / 0.187$ & 0.166 & 2.00 & \\
\hline & 04 & $0.118 / 0.148$ & 0.133 & 1.35 & \\
\hline & 05 & $0.188 / 0.194$ & 0.191 & 2.89 & \\
\hline \multirow[t]{5}{*}{ OA Group } & 01 & $0.410 / 0.414$ & 0.410 & 42.3 & $36.70 \pm 3.57^{\mathrm{c}}$ \\
\hline & 02 & $0.404 / 0.378$ & 0.391 & 35.0 & \\
\hline & 03 & $0.376 / 0.406$ & 0.386 & 38.2 & \\
\hline & 04 & $0.405 / 0.369$ & 0.387 & 34.0 & \\
\hline & 05 & $0.404 / 0.368$ & 0.386 & 34.0 & \\
\hline Treated Group & 01 & $0.275 / 0.294$ & 0.285 & 6.00 & $6.12 \pm 0.13^{\mathrm{b}}$ \\
\hline \multirow[t]{4}{*}{ (Glucosamine) } & 02 & $0.405 / 0.167$ & 0.286 & 6.10 & \\
\hline & 03 & $0.321 / 0.271$ & 0.296 & 6.30 & \\
\hline & 04 & $0.298 / 0.277$ & 0.288 & 6.20 & \\
\hline & 05 & $0.299 / 0.242$ & 0.271 & 5.99 & \\
\hline Treated Group & 01 & $0.211 / 0.308$ & 0.260 & 5.20 & $4.48 \pm 0.44^{\mathrm{ab}}$ \\
\hline \multirow{4}{*}{ (Chondroitin standard) } & 02 & $0.238 / 0.229$ & 0.234 & 4.30 & \\
\hline & 03 & $0.245 / 0.226$ & 0.236 & 4.40 & \\
\hline & 04 & $0.268 / 0.215$ & 0.242 & 4.50 & \\
\hline & 05 & $0.229 / 0.299$ & 0.229 & 4.00 & \\
\hline Treated Group & 01 & $0.216 / 0.271$ & 0.244 & 4.90 & $4.40 \pm 0.50^{\mathrm{ab}}$ \\
\hline \multirow[t]{4}{*}{ (Chondroitin sample) } & 02 & $0.195 / 0.246$ & 0.221 & 4.00 & \\
\hline & 03 & $0.217 / 0.241$ & 0.229 & 4.10 & \\
\hline & 04 & $0.246 / 0.252$ & 0.249 & 5.00 & \\
\hline & 05 & $0.231 / 0.215$ & 0.223 & 4.00 & \\
\hline Treated Group & 01 & $0.210 / 0.204$ & 0.207 & 3.20 & $2.62 \pm 0.66^{\mathrm{a}}$ \\
\hline (Chondroitin standard & 02 & $0.206 / 0.184$ & 0.195 & 3.10 & \\
\hline \multirow[t]{3}{*}{ plus glucosamine) } & 03 & $0.149 / 0.156$ & 0.153 & 1.81 & \\
\hline & 04 & $0.188 / 0.208$ & 0.198 & 3.00 & \\
\hline & 05 & $0.145 / 0.187$ & 0.166 & 2.00 & \\
\hline Treated Group & 01 & $0.147 / 0.156$ & 0.152 & 1.80 & $2.74 \pm 0.62^{\mathrm{a}}$ \\
\hline (Chondroitin sample & 02 & $0.194 / 0.200$ & 0.197 & 3.10 & \\
\hline \multirow[t]{3}{*}{ plus glucosamine) } & 03 & $0.198 / 0.210$ & 0.204 & 3.40 & \\
\hline & 04 & $0.170 / 0.184$ & 0.177 & 2.50 & \\
\hline & 05 & $0.188 / 0.194$ & 0.191 & 2.89 & \\
\hline
\end{tabular}

Means \pm S.D carrying same alphabets differ non significantly whereas with different alphabets differ significantly

concentrations in sera samples collected from rats treated with standard CS, extracted CS, GS plus standard CS and GS plus extracted CS were not significantly different than healthy rats. Difference in CTX II concentrations among groups treated with GS, standard CS and extracted CS was not significant by DMR test $(\mathrm{p} \leq 0.05)$. CTX II concentration among induced untreated group was significantly higher than all other groups (Table 2).

\section{DISCUSSION}

Osteoarthritis (OA) is a disorder of joints associated with signs of swelling, lameness and pain (McNulty et al., 2012). Knapik et al. (2014) used rat model to check the progression of OA. Experimental rodent models are preferred for smooth induction and evaluation of efficacy of different non-steroidal anti-inflammatory drugs (Zhang et al., 2008). However, combination of chondroitin sulphate (CS) and glucosamine sulphate (GS) is said to be the better treatment option for OA (Bruyere et al., 2008).

In present study, clinical scores for swelling, pain and lameness in rats treated with combinations were more close to normal than induced un-treated groups showing nonsignificant difference. Highest clinical score (4.15) was 
observed in OA rats followed by group receiving GS (3.19). Better treatment results with low level of clinical signs were observed among groups treated with combinations. Numerous therapies had been tried for treatment of OA in different experimental models. Use of NSAIDs can be decreased in OA patients by the successful therapeutic trials with CS (Bourgeois et al., 1998). In corroboration, Jawahar et al. (2012) reported highest efficacy of GS and CS combination in osteoarthritic knee recovery both in males and females. Ubelhart et al. (1998) found that CS (800 mg) reduced pain significantly and increased overall mobility in patients. Treatment was more effective and safe than symptomatic slow acting drugs in knee OA.

Nakasone et al. (2011) observed that rate of response to GS, CS and CS plus GS was 3.9 5.3 and 6.5 percent higher than placebo in line with present study. It was further added that in patients with moderate to severe pain at base line, the rate of response was significantly higher with combined therapy and reduced pain effectively. Bourgeois et al. (1998) declared that treatment with CS was significantly effective against $\mathrm{OA}$ and favored the improvement of subjective symptoms with improved joint mobility. Chou et al. (2005) stated that CS and GS together caused reduction in clinical parameters, disease incidence and interleukin-1 in sera. In arthritis associated cartilage damage, CS and GS gave better results in combination as compared to CS alone. There was variation in degree of efficacy in treatment of OA by CS and GS. However, both had potential to relieve pain and reduced joint space narrowing in OA patients (Martin et al., 2012). Long term oral administration of CS plus GS reduced cartilage degeneration and OA progression in guinea pigs (Taniguchi et al., 2012). In view of present experiment results and previous data, it is concluded that CS plus GS is best combination for the treatment of OA patients. Extracted CS showed similar efficacy as that of standard and chicken could be an easily available source.

Measurement of CTX-II concentration in OA rat sera carried out in present study was in accord with the biomarker of collagen degradation used by Garnero et al. (2003). CTX-II levels were associated with rapidly destructive OA. These findings were suggesting that this new marker might be useful for identifying patients with hip OA at high risk for rapid progressions of joint damage (Garnero et al., 2003). Raised levels of biomarker in sera indicated subsequent structural changes in the knee joint and are in accordance with clinical investigations reported by Garnero et al. (2002). Urinary CTX-II had been used as biomarker in the diagnosis and quantitative degradation of cartilage by Mazieres et al. (2006). This biomarker was used to determine the histological grading of localized affected joints and hypertrophic OA (Conrozier et al., 2007). Raised CTX-II in sera of rats was significant at early stages of joint inflammation (Oestergaard et al., 2006).
The predictive importance of CTX-II molecular marker for cartilage destruction had been undertaken in other models of destructive arthritis (Hoegh et al., 2004). Huang et al. (2014) used CTX-II serum levels to determine age related degeneration of cartilage in rabbits. CTX-II was used as an early indication of joint inflammation in the collagen induced arthritis and a reflection of progressive cartilage degradation (Oestergaard et al., 2006). Degradation product (CTX-II) of human collagen type II is slightly different from those of rodents, guinea pig, monkey, horses, dogs and chicken (Birmingham et al., 2006). ELISA has recently been used to check the synergistic effects of drugs in equine, swine and rat osteoarthritis models by Wedekind et al. (2015). However, in majority of collagenase induced OA in dogs CTX-II was undertaken as biomarker for cartilage destruction (Chu et al. 2002). Elevated levels of CTX-II persisted in sera of rats for long period in present study which is in agreement with the findings of Goranov (2007). It is concluded that CS from chicken keel cartilage and fish may reduce clinical signs of osteoarthritis.

Acknowledgments: We are highly grateful to Higher Education Commission of Pakistan for providing funds under HEC Indigenous Ph.D Scholarship Batch V 2008.

\section{REFERENCES}

Adams, T., D.B. Entrup, S. Kuhn, L. Legere, K. Mace, A. Paggi and M. Penney. 2013. Physical therapy management of knee osteoarthritis in the middle-aged athlete. Sports Med. Arthrosc. 21:2-10.

Birmingham, J.D., V. Vilim and V.B. Kraus. 2006. Collagen biomarkers for arthritis applications. Biomark Insights. $1: 61-76$

Bourgeois, P., G. Chales, J. Dehais, B. Delcambre, J.L. Kuntz and S. Rozenberg. 1998. Efficacy and tolerability of chondroitin sulfate $1200 \mathrm{mg} /$ day vs chondroitin sulfate $3 \times 400 \mathrm{mg} /$ day vs placebo. Osteoarthr. Cartilage 6:25-30.

Brandt, K.D., P. Dieppe and E. Radin. 2009. Etiopathogenesis of osteoarthritis. Med. Clin. North. Am. 93:1-24.

Bruyere, O., D. Delferriere, C. Roux, J.D. Wark, T. Spector, J.P. Devogelaer, K. Brixen, S. Adami, J. Fechtenbaum and S. Kolta. 2008. Effects of strontium ranelate on spinal osteoarthritis progression. Ann. Rheum. Dis. 67:335-339.

Chou, M.M., N. Vergnolle, J.J. McDougall, J.L. Wallace, S. Marty, V. Teskey and A. G.Buret. 2005. Effects of chondroitin and glucosamine sulfate in a dietary bar formulation on inflammation, interleukin-1 $\beta$, matrix metalloprotease-9, and cartilage damage in arthritis. Exp. Biol. Med. 230:255-262.

Chu, Q., M. Lopez, K. Hayashi, M. Ionescu, R. Billinghurst, K. Johnson, A. Poole and M. Markel. 2002. Elevation of a collagenase generated type II collagen neoepitope and 


\section{Effect of glycosaminoglycans on clinical signs of osteoarthritis}

proteoglycan epitopes in synovial fluid following induction of joint instability in the dog. Osteoarthr. Cartilage 10:662-669.

Conrozier, T., F. Ferrand, A. Poole, C. Verret, P. Mathieu, M. Ionescu, F. Vincent, M. Piperno, A. Spiegel and E. Vignon. 2007. Differences in biomarkers of type II collagen in atrophic and hypertrophic osteoarthritis of the hip: implications for the differing pathobiologies. Osteoarthr. Cartilage 15:462-467.

Fernihough, J., C. Gentry, M. Malcangio, A. Fox, J. Rediske, T. Pellas, B. Kidd, S. Bevan and J. Winter. 2004. Pain related behaviour in two models of osteoarthritis in the rat knee. Pain 112:83-93.

Flood, J. 2010. The role of acetaminophen in the treatment of Osteoarthritis-Page. Am. J. Manag. Care 16:S48-S54.

Garnero, P., T. Conrozier, S. Christgau, P. Mathieu, P. Delmas and E. Vignon. 2003. Urinary type II collagen Ctelopeptide levels are increased in patients with rapidly destructive hip osteoarthritis. Ann. Rheum. Dis. 62:939943.

Garnero, P., R.Landewe, M. Boers, A. Verhoeven, S.V.D. Linden, S. Christgau, D.V.D. Heijde, A. Boonen and P. Geusens. 2002. Association of baseline levels of markers of bone and cartilage degradation with long term progression of joint damage in patients with early rheumatoid arthritis. Arthr. Rheum. 46:2847-2856.

Garvican, E.R., A. Vaughan-Thomas, J.F. Innes and P.D. Clegg. 2010.Biomarkers of cartilage turnover. Part 1: Markers of collagen degradation and synthesis. Vet. J. 185:36-42.

Goranov, N.V. 2007.Serum markers of lipid peroxidation, antioxidant enzymatic defense, and collagen degradation in an experimental (Pond Nuki) canine model of osteoarthritis. Vet. Clin. Pathol. 36:192-195.

Hoegh, A.P., L.B. Tanko, T.L. Andersen, C.V. Lundberg, J.A. Mo, A.M. Heegaard, J.M. Delaisse and S. Christgau. 2004. Ovariectomized rats as a model of postmenopausal osteoarthritis: validation and application. Arthr. Res. Ther. 6:169-180.

Huang, C.C., C.C. Lee, C.J. Wang, F.S. Wang, H.Y. Huang, S.H. Ng, C.Y. Tseng and S.F. Ko1. 2014. Effect of Age-Related Cartilage Turnover on Serum CTelopeptide of Collagen Type II and Osteocalcin Levels in Growing Rabbits with and without Surgically Induced Osteoarthritis. BioMed. Res. Int. doi.org/10.1155/2014/284784.

Jawahar, R., S. Yang, C.B. Eaton, T. McAlindon and K.L. Lapane. 2012. Gender-specific correlates of complementary and alternative medicine use for knee osteoarthritis. J. Womens Health 21:1091-1099.

Jones, C.P., S. Carver and L.V. Kendall. 2012. Evaluation of common anesthetic and analgesic techniques for tail biopsy in mice. J. Am. Assoc. Lab. Anim. Sci. 51:808814.
Khan, H.M., M. Ashraf, A.S. Hashmi, M.D. Ahmad and A.A. Anjum. 2012. Clinical assessment of experimentally induced osteoarthritis rat model in relation to time. J. Anim. Plant. Sci. 22:960-965.

Knapik, D.M., R.K. Harrison, R.A. Siston, S. Agarwal and D.C. Flanigan. 2015. Impact of lesion location on the progression of osteoarthritis in a rat knee model. J. Ortho. Res. 33:237-245.

Martin, M.S., S.V. Sell and J. Danter. 2012. Glucosamine and chondroitin: an appropriate adjunct treatment of symptomatic osteoarthritis of the knee. Orthop. Nurs. 31: 160-166.

Mazieres, B., P. Garnero, A. Gueguen, M. Abbal, L. Berdah, M. Lequesne, M. Nguyen, J.P. Salles, E. Vignon and M. Dougados. 2006. Molecular markers of cartilage breakdown and synovitis at baseline as predictors of structural progression of hip osteoarthritis. Ann. Rheum. Dis. 65:354-359.

McNulty, M., R. Loeser, C. Davey, M. Callahan, C. Ferguson and C. Carlson. 2012. Histopathology of naturally occurring and surgically induced osteoarthritis in mice. Osteoarthr. Cartilage 20:949-956.

Miller, K.L. and D. Clegg. 2011. Glucosamine and chondroitin sulfate. Rheum. Dis. Clin. North Am. 37:103-118.

Morenko, B.J., S.E. Bove, L. Chen, R.E. Guzman, P. Juneau, T. Bocan, G.K. Peter, R. Arora and K.S. Kilgore. 2004. In vivo micro computed tomography of subchondral bone in the rat after intra-articular administration of monosodium iodoacetate. J. Am. Assoc. Lab. Anim. Sci. 43:39-43.

Nakasone, Y., K. Watabe, K. Watanabe, A. Tomonaga, I. Nagaoka, T. Yamamoto and H. Yamaguchi. 2011. Effect of a glucosamine-based combination supplement containing chondroitin sulfate and antioxidant micronutrients in subjects with symptomatic knee osteoarthritis: A pilot study. Exp. Ther. Med. 2:893-899.

Oestergaard, S., L. Chouinard, N. Doyle, S.Y. Smith, L.B. Tanko and P. Qvist. 2006. Early elevation in circulating levels of Ctelopeptides of type II collagen predicts structural damage in articular cartilage in the rodent model of collagen induced arthritis. Arthr. Rheum. 54:2886-2890.

Sofat, N., I. Beith, P.G. Anilkumar and P. Mitchell. 2011. Recent clinical evidence for the treatment of osteoarthritis: What we have learned. Rev. Recent. Clin. Trials 6:114-126.

Taniguchi, S., J. Ryu, M. Seki, T. Sumino, Y. Tokuhashi and M. Esumi. 2012. Long-term oral administration of glucosamine or chondroitin sulfate reduces destruction of cartilage and up-regulation of MMP-3 mRNA in a model of spontaneous osteoarthritis in Hartley guinea pigs. J. Orthop. Res. 30:673-678. 
Uebelhart, D., E.J. Thonar, P.D. Delmas, A. Chantraine and E. Vignon. 1998. Effects of oral chondroitin sulfate on the progression of knee osteoarthritis: a pilot study. Osteoarthr. Cartilage 6:39-46.

Wedekind, K.J., J.A. Coverdale, T.R. Hampton, C.A. Atwell, R.H. Sorbet, J. Lunnemann, R.J. Harrell, L. Greiner, N.K. Keith, J.L Evans, J. Zhao, and C.D. Knight. 2015. Efficacy of an equine joint supplement, and the synergistic effect of its active ingredients (chelated trace minerals and natural eggshell membrane), as demonstrated in equine, swine, and an osteoarthritis rat model. Open Access Anim. Physiol. 7:13-27.

Zhang, W., G. Nuki, R. Moskowitz, S. Abramson, R. Altman, N. Arden, S. Bierma-Zeinstra, K. Brandt, P. Croft and M. Doherty. 2010. OARSI recommendations for the management of hip and knee osteoarthritis: part III: Changes in evidence following systematic cumulative update of research published through January 2009. Osteoarthr. Cartilage 18:476-499. 